\title{
Cien años de movimiento social en Nicaragua. Relato cronológico
}

Autor: Onofre Guevara

\section{Prólogo por José Luis Rocha}

Cuatro hechos se reúnen para hacer que este libro sea atípico y ayude a llenar un gigantesco agujero negro en la historiografía nicaragüense. En primer

lugar, su contraste con los historiadores tradicionales, su carácter excepcional en la elección de los sujetos de la historia. La mayoría de los historiadores nicaragüenses -las más de las veces miembros de las élites- se contentan con engarzar genealogías, rastrear la evolución de un rubro agropecuario y dar cuenta de los grandes episodios protagonizados -naturalmente- por los dominantes. Los textos escolares de historia y las ilustraciones de la llamada "semana de la patria" están plagados de prósperos aristócratas que lucen gigantescas patillas y luctuosas

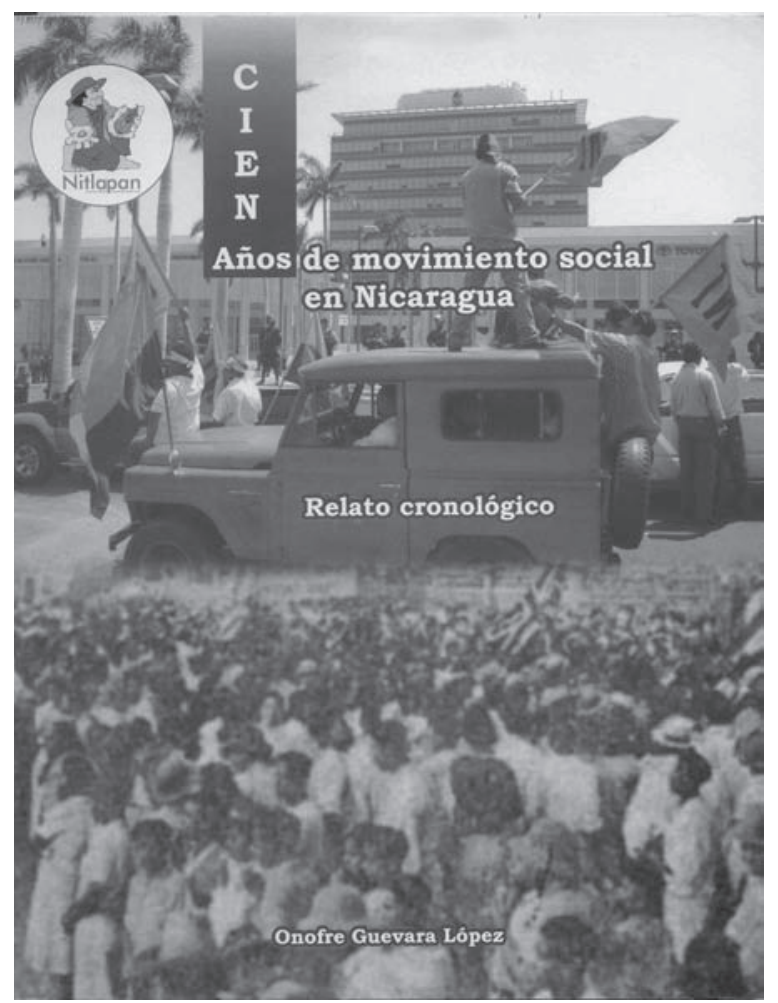
levitas. El mensaje es nítido: la historia la hacen las botas, nunca los caites. La dominación de las élites, para ser contundente, se auxilia con una historiografía incompleta y sesgada, que nos han hecho mamar en los textos escolares y los soporíferos discursos de gobernantes interesados en rescatar las presuntas hazañas de sus predecesores. No se ha hecho justicia al ruido de los caites que muchas veces hizo correr despavoridas a las botas y tacones altos. Este libro revierte ese sesgo: está lleno de nombres que para la mayor parte de los lectores resultarán desconocidos. Ya es hora de que les suenen familiares. Quizás algunos recuerden a Francisco Bravo Lacayo por la columna de análisis político que en la página de opinión de El Nuevo Diario publicó religiosamente durante décadas. Pero ésaben que fue Presidente de la Central General de Trabajadores y que representó a los obreros nicaragüenses en numerosos congresos internacionales? Este libro está también lleno de hechos poco conocidos. ¿Cuántos saben que FETSALUD tiene en Silvia Ferrufino una mártir memorable, que Domingo Sánchez Salgado "Chagüitillo" fue uno de los líderes que Somoza nunca pudo comprar y que el poeta Salomón de la Selva llegó a figurar entre los principales 
líderes del movimiento obrero nicaragüense en León? Gremios, sindicatos y obreros son homenajeados en estas páginas que deberían inspirar unas genuinas fiestas patrias.

En segundo lugar, este libro tiene una solidez ideológica atípica. Rezuma materialismo histórico. No obstante su prosa clara, concisa y sencilla, se inscribe en una tradición de pensamiento donde el rigor analítico y el compromiso ético-político se funden para engendrar una visión que es coherente y rinde tributo a quienes luchan por la justicia. Estas virtudes lo colocan a contrapelo de las modas de pensamiento de ahora y otrora. Por su vínculo a una teoría marxista de los procesos históricos, se distancia de las tradicionales historiografías anecdóticas, que se conforman con novelar los devaneos de los cortesanos. Por su toma de partido a favor de los obreros organizados, rompe con la asepsia tecnócrata que prefiere hablar de incentivos, y no de reivindicaciones; de mercados de objetos, y no de salarios de sujetos; y de rubros productivos antes que de gremios, grupos o federaciones de productores.

En tercer lugar, este libro fue escrito por un obrero, que lleva varios libros en su haber. El zapatero Onofre Guevara fue protagonista destacado de las luchas que describe. Como Miguel Mármol, vivió lo que narra. Y además lo narra con su propia y muy diestra pluma. Pluma adiestrada, pero no domesticada. Este zapatero sabe cuál es la horma de los zapatos de la burguesía. Por eso no retoma sus incoloros textos. Narra lo que vivió y lo que vivieron sus pares en un libro testimonial y basado en testimonios de los protagonistas. Esta es una historia basada en fuentes primarias y narrada con la convicción de quien se ha jugado la vida por la causa de los obreros.

Los obreros no han podido publicar muchos libros en este país. Y la mayoría de los libros, boletines y periódicos que produjeron no están al acceso de los estudiantes, investigadores y obreros. Probablemente desaparecieron, o yacen en bibliotecas particulares. Pero no están en las bibliotecas colectivas. Fueron víctimas de la selección que los archivadores emprenden con los criterios de los dominantes. Este libro rescata mucho de lo que esa selección nos niega. Aquí los obreros tienen voz y pluma propias. Oigámoslos, leámoslos.

Finalmente, este libro es atípico y urgente en la coyuntura actual, una época en que la mano visible de la Guardia Nacional ha sido sustituida por formas menos ostentosas aunque no totalmente nuevas- de represión: el desempleo masivo, la mordaza financiera y la manipulación partidista. El desempleo masivo es el aliado de la flexibilidad laboral, esa forma de precarización del trabajo caracterizada por la inestabilidad laboral y la externalización de los costos de producción. Las empleadas y empleados no tienen trabajo estable, la rotación es muy acelerada y la distribución de costos del proceso productivo está organizada de tal manera que los trabajadores deben asumir parte de los mismos. Esta flexibilización laboral tiene como condición de posibilidad las altas tasas de desempleo: los patrones saben que hay un ejército de desempleados dispuestos a aceptar cualquier tipo de contrato. Estas y otras situaciones no pueden ser denunciadas en los medios de comunicación. La mordaza financiera se impone. Ningún medio cubre las demandas de los cientos de trabajadores que enfermaron de insuficiencia renal crónica como consecuencia del uso de pesticidas en las plantaciones de la familia Pellas. ¿Qué medio de comunicación podría prescindir de la publicidad del descomunal abanico de empresas del grupo Pellas? A 
callar. La mordaza financiera siempre ha tenido mejor puntería y alcance que los fusiles. En estas condiciones, este libro ofrece a los obreros de hoy un recorrido por sus luchas y, por ello, una muestra de su poder y de la tradición a la que pertenecen.

La subida al poder del FSLN, tras años de gobernar desde abajo basándose en parte en la manipulación de las organizaciones populares, podría significar una reedición del verticalismo que caracterizó las relaciones entre el FSLN y los gremios y asociaciones en la década de los 80. Cooptando, sobornando y embaucando a líderes y organismos el FSLN podría consolidar su modelo político dictatorial y un modelo económico-social que el sociólogo estadounidense James Petras ha llamado "neoliberalismo pragmático". Ahora que algunas de esas organizaciones sociales experimentan crisis y eventuales choques con el FSLN, este libro tiene la función de sembrar la alarma y explicar a las trabajadoras y trabajadores cómo sus luchas sociales han sido frenadas, manipuladas, debilitadas y corrompidas por la represión, la demagogia, las falsas promesas y el dinero de los dominantes, independientemente de su color político: somocistas, empresarios, alemanistas o cúpula sandinista.

"Cien años de movimiento social en Nicaragua" abre el apetito sobre los movimientos sociales en Nicaragua. Como lector, imagino cuánta historia hay detrás de las huelgas, congresos, discusiones y cismas que aquí, por la naturaleza y pretensiones de este texto, apenas han quedado reseñados. Cada nombre sin duda carga una biografía política densa y enjundiosa. Las luchas femeninas y otras formas de movimientos sociales no sindicales o gremiales son otros de los muchos retos para completar este impresionante recorrido cronológico. Para que continúen su labor de historiadores: larga vida y buena memoria para Onofre y sus pares.

José Luis Rocha 